\title{
Compositional Homogenization of Electrodeposited High Entropy Alloys Coatings for Enhanced Corrosion Resistance
}

\author{
AHMED ALIYU ${ }^{1}$ and Chandan Srivastava ${ }^{2}$ \\ ${ }^{1}$ Indian Institute of Science, Bangalore, United States, ${ }^{2}$ IISc Bangalore, Bengaluru, Karnataka, India
}

New class of metallic materials called the high entropy alloys (HEAs), which consist of five or more elements in a near equi-atomic ratio, have received significant attention due to their exceptional properties [1, 2]. Among the $\mathrm{HEAs}$, the $\mathrm{AlFeCoNiCu}$ and $\mathrm{AlCrFeCoNiCu}$ alloys have attracted attention due to their excellent corrosion and mechanical properties [3]. This work illustrates the role of graphene oxide (GO) in enhancing the corrosion resistance behaviour of $\mathrm{AlFeCoNiCu}-\mathrm{GO}$ and $\mathrm{AlCrFeCoNiCu}-\mathrm{GO}$ composite $\mathrm{HEA}$ coatings by inducing compositional homogenization.

Graphene oxide (GO) was synthesized by the modified Hummer's method [2]. The pristine HEAs coating and HEAs-GO composite coatings were electrodeposited over mild steel substrate using a DC power source. The coatings bath contained chloride salts of $\mathrm{Al}, \mathrm{Cr}, \mathrm{Fe}, \mathrm{Co}, \mathrm{Ni}$, and $\mathrm{Cu}$ at an optimized concentration. For HEAsGO coatings, $3.125 \mathrm{~g} / \mathrm{l}$ of GO was dispersed into the electrolyte solution. The electrolyte's $\mathrm{pH}$ was maintained at 1.5. $15 \mathrm{~min}$ deposition time was applied. The current density used was $160 \mathrm{~mA}$ and $200 \mathrm{~mA}$ for $\mathrm{AlFeCoNiCu}$ and $\mathrm{AlCrFeCoNiCu}$ HEAs coatings, respectively.

Transmission electron microscopy (TEM) bright-field image and compositional map of AlFeCoNiCu HEAs coating in Figures 1(a) and (c) reveal the presence of highly Al-rich matrix phase and $\mathrm{Co}, \mathrm{Ni}, \mathrm{Cu}$, and $\mathrm{Fe}$ containing dendritic phase in the coating microstructure. However, with GO addition, the Al-rich phase becomes uniformly distributed within the dendritic phase of the coating microstructure (Figure 1(b) and (d)). Similarly, the TEM image and the compositional map of the AlCrFeCoNiCu HEAs coating in Figures 2(a) and (c) show a heterogeneous microstructure with two distinct phases, namely: (i) $\mathrm{Cu}$-rich phase with $\mathrm{Fe}$, $\mathrm{Co}$, and Ni element, and (ii) Al-rich phase with Cr element. It can be noticed that in this case also, the microstructure (TEM image in Figure 2(b); Compositional mapping in Figure 2(d)) becomes nearly homogenous after GO addition.

The corrosion analysis data (performed in $3.5 \mathrm{wt} \% \mathrm{NaCl}$ solution) of the $\mathrm{AlFeCoNiCu}$ and $\mathrm{AlCrFeCoNiCu}$ HEAs with/without GO is presented in Figures $1(\mathrm{e}-\mathrm{g})$ and $2(\mathrm{e}-\mathrm{g})$, respectively. From the Tafel polarization curves in Figures 1(f) and 2(f), the corrosion parameters: corrosion current density ( $\left.i_{\text {corr }}\right)$ and corrosion potential $\left(\mathrm{E}_{\text {corr }}\right)$ were obtained and are plotted in Figures $1(\mathrm{~g})$ and $2(\mathrm{~g})$. The $\mathrm{E}_{\text {corr }}$ values are $-0.78 \mathrm{~V}$ and $-0.686 \mathrm{~V}$, and $\mathrm{i}_{\text {corr }}$ values are $123.3 \mu \mathrm{A} / \mathrm{cm}^{2}$ and $20.45 \mu \mathrm{A} / \mathrm{cm}^{2}$, respectively, for AlFeCoNiCu and $\mathrm{AlFeCoNiCu}-\mathrm{GO}$ coating. In case of $\mathrm{AlCrFeCoNiCu}$ and $\mathrm{AlCrFeCoNiCu}-\mathrm{GO}$ coating, the $\mathrm{E}_{\text {corr }}$ values are $-0.717 \mathrm{~V}$ and $-0.641 \mathrm{~V}$, and $\mathrm{i}_{\text {corr }}$ values are $93.67 \mu \mathrm{A} / \mathrm{cm}^{2}$ and $12.84 \mu \mathrm{A} / \mathrm{cm}^{2}$, respectively. The shift in the $E_{\text {corr }}$ value towards the positive potential and decreases in the $\mathrm{i}_{\text {corr }}$ value of the HEAs-GO coatings indicates an enhancement in the coatings' corrosion resistance compared to the pristine HEAs.

The observed decrease in pristine HEAs' corrosion resistance resulted from the element segregation, which leads to galvanic coupling and localization of the corrosive attack. In contrast, the observed enhancement in the corrosion resistance of the HEAs-GO composite coatings is due to the microstructural homogenization caused by GO incorporation in addition to GO impermeability, which prevents the penetration of corrosive media. 

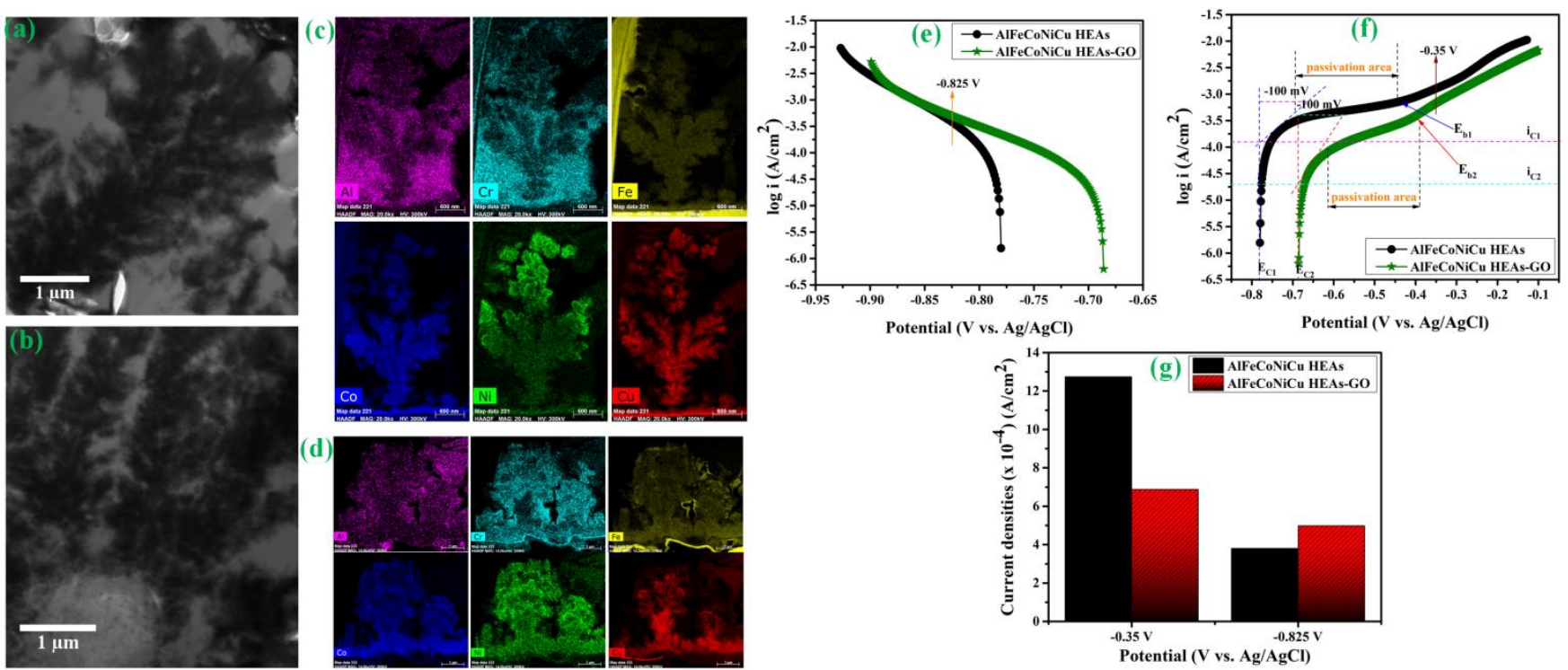

Figure 1. Figure 1. AlFeCoNiCu HEAs (a) TEM image without GO (b) TEM image with GO (c) Compositional mapping without GO (d) Compositional mapping with GO (e) cathodic branches of the Tafel curves (f) anodic branches of the Tafel curves (g) corrosion parameters.
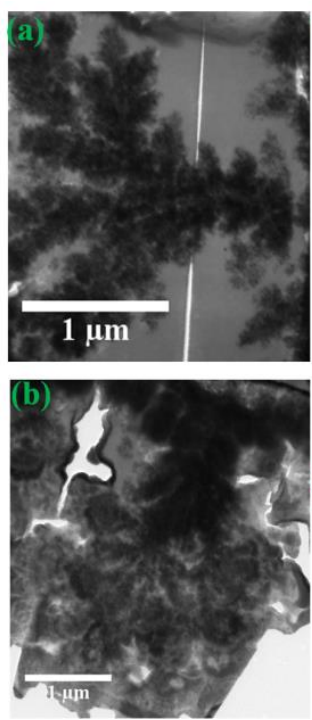
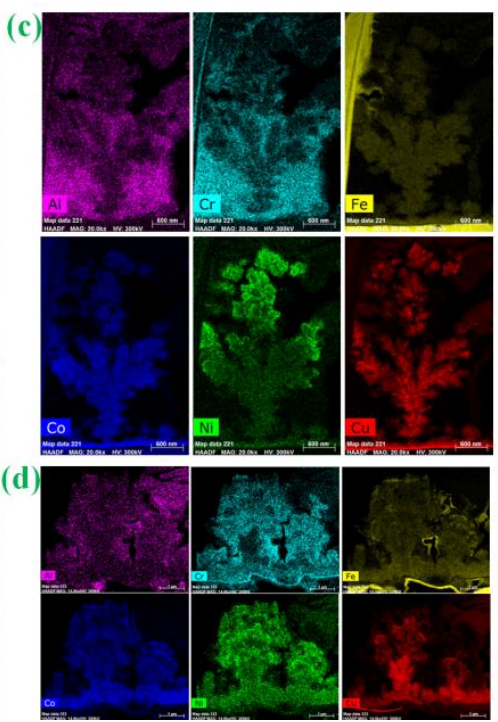
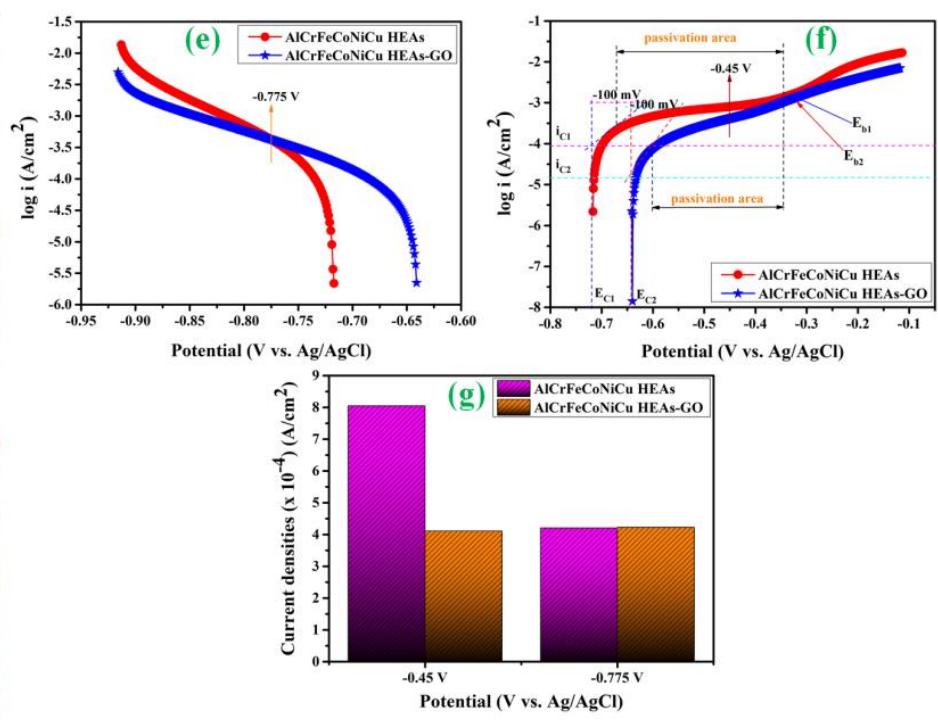

Figure 2. Figure 2. AlCrFeCoNiCu HEAs (a) TEM image without GO (b) TEM image with GO (c) Compositional mapping without GO (d) Compositional mapping with GO (e) cathodic branches of the Tafel curves (f) anodic branches of the Tafel curves (g) corrosion parameters.

\section{References}

[1] B. Cantor, I.T.H. Chang, P. Knight, A.J.B. Vincent, Mater. Sci. Eng. A 375-377 (2004), p. 213-218.

[2] A. Aliyu, C. Srivastava, Materilia 5 (2019), p. 100249.

[3] J.W. Yeh, S.K. Chen, S.J. Lin, J.Y. Gan, T.S. Chin, T.T. Shun, C.H. Tsau, S.Y. Chang, Adv. Eng. Mater. 6 (2004), p. 299-303. 